\title{
Penerapan Teknologi Penanaman Mangrove di Kabupaten Mempawah Provinsi Kalimantan Barat, Indonesia
}

\section{Application of Mangrove Planting Technology in Kabupaten Mempawah, West Kalimantan, Indonesia}

\author{
${ }^{1}$ Laili Fitria, ${ }^{1}$ Yulisa Fitrianingsih, 1 Jumiati \\ ${ }^{1}$ Jurusan Teknik Lingkungan, Fakultas Teknik, Universitas Tanjungpura, Pontianak \\ Korespondensi: Laili Fitria, fitria.laili@gmail.com
}

Naskah Diterima: 14 September 2019. Disetujui: 26 Januari 2020. Disetujui Publikasi: 17 Februari 2020

\begin{abstract}
In 11 years there has been a change in the mangrove ecosystem around 76,000 ha or $36 \%$ of its original area in West Kalimantan. Damage to the coastal area of Kabupaten Mempawah in Desa Sungai Kunyit due to abrasion. The impact felt by the surrounding community is the decline in fisheries production. However, in the last few years, it has been known that in Kabupaten Mempawah mangrove conservation has been carried out, especially in preventing abrasion on degraded land. However, most mangrove plantations fail to grow. The purpose of this writing is to explain the community-based mangrove conservation in Kabupaten Mempawah which has been done to overcome the failure of mangrove planting that has been done. The method in mangrove conservation is carried out with mangrove planting training, followed by preparation and search for mangrove seedlings, seeding mangrove seeds, planting mangrove seedlings by stake, conservation evaluation. As a result of this activity, mangrove plants are in the range of $60-70 \%$ which still survives. The proven stake can increase the chances of survival of mangrove seedlings planted on the coast. A management group for Mempawah mangrove ecosystem has also been formed. Conservation in mangrove ecosystem forests must involve many parties, communities, village governments, local governments, the private sector, community, youth organizations, and others. Conservation in Kabupaten Mempawah is carried out with an emphasis on empowering local communities, commonly known as the bottom-up approach.
\end{abstract}

Keywords: Community, conservation, mangrove, Mempawah.

\begin{abstract}
Abstrak. Dalam 11 tahun telah terjadi perubahan ekosistem mangrove sekitar 76.000 hektare atau 36\% dari wilayah aslinya di Kalimantan Barat. Kerusakan wilayah pesisir Kabupaten Mempawah di Sungai Kunyit dikarenakan abrasi. Dampak yang dirasakan oleh masyarakat sekitar adalah menurunnya produksi perikanan. Namun dalam beberapa tahun terakhir, diketahui bahwa di Kabupaten Mempawah telah melakukan konservasi mangrove, terutama dalam pencegahan abrasi pada lahan yang sudah kritis. Namun sebagian besar penanaman mangrove gagal tumbuh. Penulisan ini bertujuan untuk memaparkan konservasi mangrove berbasis masyarakat di Kabupaten Mempawah yang telah dilakukan untuk mengatasi kegagalan penanaman mangrove yang pernah dilakukan. Metode dalam konservasi mangrove ini dilakukan dengan pelatihan penanaman mangrove, dilanjutkan dengan persiapan dan pencarian bibit mangrove, penyemaian bibit mangrove, penanaman bibit mangrove dengan ajir, evaluasi konservasi. Hasil kegiatan ini, tanaman mangrove berada di kisaran 60-70\% yang masih bertahan hidup. Terbukti ajir bisa menambah peluang hidup bibit mangrove yang ditanam di pesisir pantai. Juga telah terbentuk kelompok pengelola ekosistem mangrove Mempawah. Konservasi di hutan ekosistem mangrove harus melibatkan banyak pihak, masyarakat, pemerintah desa, pemerintah daerah, sektor swasta, organisasi masyarakat/masyarakat, organisasi pemuda, dan lainnya. Konservasi di Kabupaten Mempawah
\end{abstract}


dilakukan dengan penekanan pada pemberdayaan masyarakat lokal yang umumnya dikenal sebagai pendekatan bottom-up.

Kata Kunci: komunitas, konservasi, mangrove, Mempawah.

\section{Pendahuluan}

Indonesia memiliki hutan mangrove dengan luas 4,13 hektare. Luas area asal mangrove berdasarkan seri RePPProT (1958-1989) dari peta status hutan, tata guna lahan dan sistem lahan. Dari penghitungan, diketahui luas mangrove yang tersisa pada tahun 1990 hanya sekitar 2,49 juta hektare (60\%). Dari luasan areal mangrove yang tersisa tersebut, 58\% diantaranya terdapat di Papua, dan hanya $11 \%$ tersisa di Jawa. Untuk kawasan di luar jawa dan Papua, perubahan areal tersebut terjadi sangat beragam (Giesen, 1993).

Kalimantan Barat merupakan salah satu provinsi di Indonesia dengan garis pantai sepanjang $1.940 \mathrm{Km}$ yang didominasi oleh ekosistem mangrove di pesisir pantainya. Diketahui bahwa Kalimantan Barat memiliki 213.000 hektare hutan mangrove tahun 1991. Berdasarkan data dari Baplan tahun 2002, Kalimantan Barat memiliki 137.000 hektare (Noor, dkk., 2012). Berarti dalam waktu 11 tahun telah terjadi perubahan ekosistem mangrove sekitar 76.000 hektare atau $36 \%$ dari luasan semula. Sehingga perubahan ekosistem mangrove per tahun adalah 6.909 hektare.

Wilayah pesisir terdiri dari berbagai ekosistem, salah satunya adalah ekosistem hutan mangrove. Ekosistem hutan mangrove ini sangat penting, karena memiliki nilai ekonomi yang dapat dimbil langsung (misalnya batang, akar, daun, dan buah), ekosistem mangrove juga berperan terhadap perekonomian pantai secara tidak langsung. Ekosistem hutan mangrove (EHM) mendukung keberadaan ekosistem lain di sekitarnya, misalnya perikanan pantai, terumbu karang, dan padang lamun (Siburian \& Haba, 2016).

Sebagai bagian dari wilayah pesisir, berdasarkan metode penentuan fungsi hutan, mangrove dibedakan menjadi empat kuadran. Fungsi yang berada di kuadran pertama adalah barang dan jasa yang dihasilkan atau dapat diambil dari ekosistem itu sendiri dan dapat dipasarkan. Hasilnya, meliputi kepiting dan kerang. Fungsi EHM pada kuadran kedua ditemui di luar ekosistem, tetapi masih memiliki pasar. Hasilnya antara lain udang putih, bandeng, kakap, belanak. Fungsi hutan mangrove pada kuadran ketiga, tidak memiliki pasar, yang meliputi hutan bakau pada fungsi medis, sebagai daerah asuhan dan pemijahan ikan, daerah penelitian dan laboratorium alam. Sementara itu, kuadran keempat berada di luar ekosistem mangrove dan tidak memiliki pasar, contohnya penahan erosi tanah di sepanjang pesisir, penahan gelombang pasang surut (Yani, dkk., 2006).

Kementerian Kehutanan pada 2007, melalui Direktur Bina Rehabilitasi Hutan dan Lahan Kementerian Kehutanan (2009) mengeluarkan data hutan mangrove Indonesia, luasnya mencapai $7.758 .410,595$ hektare, tetapi hampir $70 \%$ mengalami kerusakan (Siburian \& Haba, 2016). Hal yang sama juga terjadi pada ekosistem mangrove yang ada di Pesisir Kabupaten Mempawah, Kalimantan Barat.

Kerusakan wilayah pesisir Kabupaten Mempawah tepatnya Kecamatan Sungai Kunyit terjadi karena adanya abrasi pantai dengan lebar rata-rata berkisar antara 250-1.250 m dalam kurun waktu 20 tahun (Bapedalda Kalimantan Barat, 2003). Dampak yang sangat dirasakan oleh masyarakat sekitar adalah penurunan produksi perikanan. Berdasarkan data Dinas Perikanan Kalimantan Barat dalam BPS Kalimantan Barat 2002, jumlah hasil perikanan di sekitar muara sungai dan rawa-rawa tahun 1997 yaitu 24.000 ton, sedangkan produksinya tahun 2001 menurun menjadi 14.000 ton. Hal ini berarti, dalam kurun waktu 4 tahun telah terjadi penurunan produksi perikanan sebesar 10.000 ton atau sekitar 2.500 ton per tahun. 
Kecamatan Sungai Kunyit merupakan kawasan yang mengalami abrasi pantai terparah yaitu sekitar $50 \mathrm{~m}$ dari bibir pantai sebelumnya dan hampir mencapai jalan raya yang menghubungkan kota Pontianak dan kota Singkawang. Abrasi pantai yang terjadi, akibat dari perubahan tata guna lahan dari hutan mangrove menjadi wilayah pemukiman. Rusaknya ekosistem mangrove berdampak terhadap berkurangnya keanekaragaman hayati dan populasi biota laut yang menjadi sumber mata pencaharian utama masyarakat di Kecamatan Sungai Kunyit selain bertani. Selain itu, dampak tidak langsung dari kerusakan ekosistem mangrove adalah penurunan kualitas air. Hal ini disebabkan karena hilangnya adsorben bahan pencemar (polutan).

Upaya pencegahan abrasi telah dilakukan dengan membuat pemecah ombak di sepanjang bibir pantai. Selain itu juga sudah pernah dilakukan penanaman tanaman mangrove, namun sebagian besar mengalami kegagalan. Mangrove yang telah ditanam, tidak tumbuh, juga banyak yang hilang setelah penanaman dilakukan. Berdasarkan hasil wawancara, sebagian besar masyarakat berasumsi bahwa kegagalan yang terjadi hanyalah karena faktor alam (gelombang dan angin laut).

Pembentukkan ekosistem mangrove juga sering mengalami hambatan. Agar ekosistem mangrove terbentuk, diperlukan pengetahuan dan pengamatan lapangan mengenai lokasi tanam, substrat pendukung, faktor abiotik, kesesuaian bibit, dan pemeliharaan pascatanam. Hal-hal ini kurang diperhatikan dalam kegiatan penanaman yang telah dilakukan. Masyarakat kurang dibekalkan pengetahuan mengenai tanaman mangrove dan ekosistem mangrove serta metode yang dapat diaplikasikan dalam penanaman dan pemeliharaan pasca tanam.

Kondisi krisis pengetahuan merupakan kendala yang membutuhkan perhatian khusus dan kekonsistenan. Semakin menurunnya luasan ekosistem mangrove yang disebabkan oleh kebutuhan akan lahan pemukiman dan tanam adalah permasalahan yang tidak berujung. Solusi yang dapat mengubah keadaan tersebut adalah kesadaran dan tindakan nyata dari masyarakat sekitar untuk membangun wilayahnya. Juga diperlukan tindakan perbaikan mulai dari penangangan pencegahan abrasi pantai dengan penanaman kembali tanaman mangrove, pemberian pelatihan berupa pengelolaan hasil hutan mangrove (Ahmad, 2017).

Menjawab permasalahan yang dihadapi mitra, melalui kegiatan ini akan dilakukan pertemuan dengan masyarakat Desa Mendalok dan Desa Sungai Duri II dalam bentuk kegiatan pelatihan. Kegiatannya adalah melakukan sosialisasi dan pelatihan kepada anggota masyarakat Desa Mendalok dan desa Sungai Duri II Kecamatan Sungai Kunyit, Kabupaten Mempawah, Kalimantan Barat tentang cara penanaman dan pemeliharaan mangrove. Tujuan dari kegiatan ini yakni penguatan pengetahuan dan meningkatkan kesadaran masyarakat terhadap pentingnya konservasi mangrove. Manfaat dari kegiatan ini antara lain mengurangi abrasi pesisir pantai Desa Mendalok dan Desa Sungai Duri II dengan meningkatkan keberhasilan penanaman mangrove, dengan cara pengikatan bibit mangrove pada bambu/ajir. Manfaat lainnya adalah terbentuknya komunitas masyarakat pencinta mangrove yang akan melanjutkan program konservasi.

\section{Metode Pelaksanaan}

Tempat dan Waktu. Tempat pelaksanaan kegiatan ini adalah di Desa Mendalok dan Desa Sungai Duri II di Kabupaten Mempawah Provinsi Kalimantan Barat. Waktu pelaksanaan pada Bulan Maret hingga Oktober 2016.

Khalayak Sasaran. Sasaran kegiatan ini antara lain penduduk Desa Mendalok dan penduduk Desa Sungai Duri II yang mengalami masalah kondisi lahan yang abrasi. Penduduk Desa tersebut juga mengeluh kesulitan dalam memperoleh air 
tawar (khususnya yang berbatasan dengan pantai). Penduduk Desa merasa perlu pemerataan kesadaran akan pentingnya ekosistem mangrove.

Metode Pengabdian. Metode yang digunakan pada kegiatan ini adalah metode partisipatori dan kolaboratif. Keberhasilan kegiatan ini dengan menggunakan metode partisipatori sangat ditentukan oleh partisipasi dari masyarakat yang menjadi sasaran dari kegiatan ini. Masyarakat akan dilibatkankan secara langsung dalam kegiatan ini mulai dari proses perencanaan, penanaman dan pemeliharaan. Sedangkan metode kolaboratif merupakan bentuk kerjasama antara pihak perguruan tinggi dan pemerintah dalam upaya pemberdayaan masyarakat dengan membentuk kelompok masyarakat yang akan dibina.

Upaya yang akan dilakukan untuk mengimplementasikan kegiatan ini menggunakan 2 metode yaitu:

A. Metode Partisipatori.

Tahapan yang akan dilakukan dalam metode partisipatori yaitu melakukan pertemuan dengan kepala desa dan beberapa tokoh masyarakat setempat mengenai kegiatan yang akan dilakukan, melakukan wawancara langsung mengenai dampak yang dirasakan oleh masyarakat akibat kerusakan ekosistem mangrove serta memberi pengarahan agar masyarakat ikut berpartisipasi dalam kegiatan ini.

B. Metode Kolaboratif.

Untuk mencapai tujuan dari kegiatan ini, harus mendapat dukungan dari pemerintah setempat dan para stakeholders dengan melakukan kerja sama. Dalam metode kolaboratif, integrasi antar elemen yaitu masyarakat, pemerintah dan stakeholders adalah mutlak. Pemerintah sebagai pembuat kebijakan dan pengambil keputusan harus dapat meyakinkan masyarakat akan pentingnnya fungsi mangrove bagi kehidupan biota laut dan dampaknya terhadap masyarakat. Sedangkan peran stakeholders, yaitu sebagai penggerak dan pendukung kegiatan ini berupa bantuan moril maupun materiil untuk mencapai tujuan bersama-sama, seperti aktivis lingkungan, pengusaha ikan, pengusaha kebun dan lain-lain. Adapun dinas yang akan dijadikan sebagai mitra dalam kegiatan ini yaitu Dinas Kehutanan Kabupaten Mempawah dan Dinas Perikanan Kabupaten Mempawah. Komunitas masyarakat yang menjadi penggerak dalam kegiatan adalah komunitas Pencinta Mangrove.

Adapun tahapan pelaksanaan kegiatan ini dilakukan dengan metode $3 \mathrm{P}$ (Perencanaan, Penanaman dan Pemeliharaan), yaitu:

A. Perencanaan.

Perencanaan penanaman yang akan dilakukan dengan memperhatikan kondisi lapangan lokasi yang akan ditanami mangrove. Pemilihan lokasi penanaman mangrove diarahkan untuk memperbaiki kondisi pantai dan memperbaiki ekosistem mangrove yang menjadi habitat bagi biota laut.

B. Penanaman Mangrove.

Penanaman dilakukan dengan 2 teknik, yaitu (1) bibit mangrove ditanam langsung pada kawasan pesisir dengan membuat lubang tanam, (2) penanaman dilakukan dengan cara memasukkan bibit mangrove pada selongsong bambu atau bibit mangrove diikat pada bambu/ajir. Tujuannya adalah untuk memperkuat dan melindungi batang bibit mangrove dari terjangan ombak.

C. Pemeliharaan.

Pemeliharaan dilakukan dengan cara melakukan monitoring setiap harinya, melakukan perawatan apabila ada bibit mangrove yang tumbang dan terseret arus/ombak. Pemeliharaan mangrove juga dapat dilakukan dengan membuat pagar kecil agar tidak ada masyarakat yang menangkap ikan atau udang di daerah yang baru ditanami tersebut.

Indikator Keberhasilan. Indikator dari keberhasilan penerapan teknologi penanaman mangrove antara lain terbentuknya masyarakat pencinta mangrove Jurnal Panrita Abdi, 2020, Volume 4, Issue 2. 
yang akan melanjutkan program konservasi. Adanya buku panduan mengenai Penanaman dan Pemeliharaan Mangrove. Dalam jangka panjang, diharapkan berkurangnya abrasi pesisir pantai di Desa Mendalok dan Desa Sungai Duri II.

Metode Evaluasi. Metode evaluasi dilakukan dengan melakukan kunjungan ke lapangan setelah dilakukan penanaman mangrove bersama-sama masyarakat untuk memperoleh tanaman mangrove yang telah ditanam dalam jangka waktu 1 bulan dan 3 bulan setelah penanaman. Selain itu juga dilakukan komunikasi berkelanjutan terhadap komunitas pecinta mangrove dan karang taruna di desa mitra.

\section{A. Persiapan dan Pencarian Bibit Mangrove}

\section{Hasil dan Pembahasan}

Kegiatan ini dengan menggunakan metode partisipatori yang sangat ditentukan oleh partisipasi dari masyarakat yang menjadi sasaran dari kegiatan ini. Masyarakat dilibatkan secara langsung dalam kegiatan ini mulai dari proses perencanaan, penanaman dan pemeliharaan. Kegiatan dimulai dengan tahapan persiapan dan survei awal, serta perijinan. Diawali dengan rapat seluruh anggota tim dengan melibatkan mahasiswa Prodi Teknik Lingkungan Untan. Selanjutnya adalah menyusun jadwal kegiatan agar sesuai dengan jadwal masyarakat dan bisa selesai tepat waktu.

Kegiatan perijinan dimulai dengan permohonan ijin dengan Kepala Desa Sungai Duri II Kabupaten Mempawah sebagai lokasi terpilih yang akan dibuat Kelompok Ekosistem Pemelihara Mangrove. Selain itu juga dilakukan permohonan ijin dengan Kepada Desa Mendalok Kabupaten Mempawah, juga diharapkan partisipasi masyarakat dalam pencarian bibit mangrove. Desa Mendalok dikenal sebagai desa penjualan bibit Mangrove.

Selanjutnya adalah tahapan pencarian benih mangrove bersama-sama masyarakat Desa Mendalok Kabupatan Mempawah (Gambar 1). Pencarian benih mangrove dilakukan di dalam Hutan Lindung Desa Mendalok. Peralatan untuk pembibitan sudah disiapkan sebelumnya. Pembelian alat-alat dilakukan di Kota Pontianak dan Mempawah.

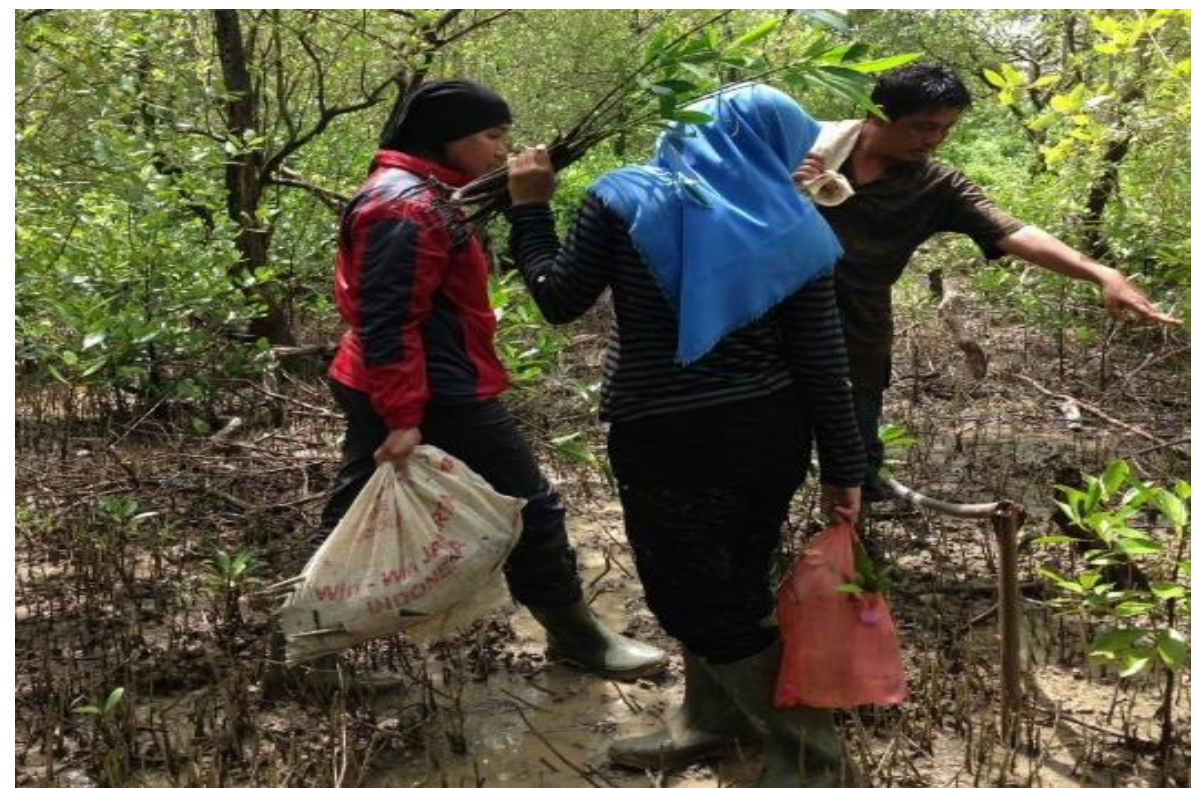

Gambar 1. Proses pencarian benih mangrove bersama warga Desa Mendalok

Proses pencarian benih mangrove yakni mengambil buah mangrove dari pohonnya secara langsung, yaitu buah yang sudah matang, yang ditandai dengan 
adanya cincin kuning di bagian propagulnya (buah Rhizophora). Benih mangrove kemudian dikumpulkan, dipilih, dilakukan perhitungan jumlah benih yang terkumpul kemudian diletakkan di tempat yang terlindung (Gambar 2).

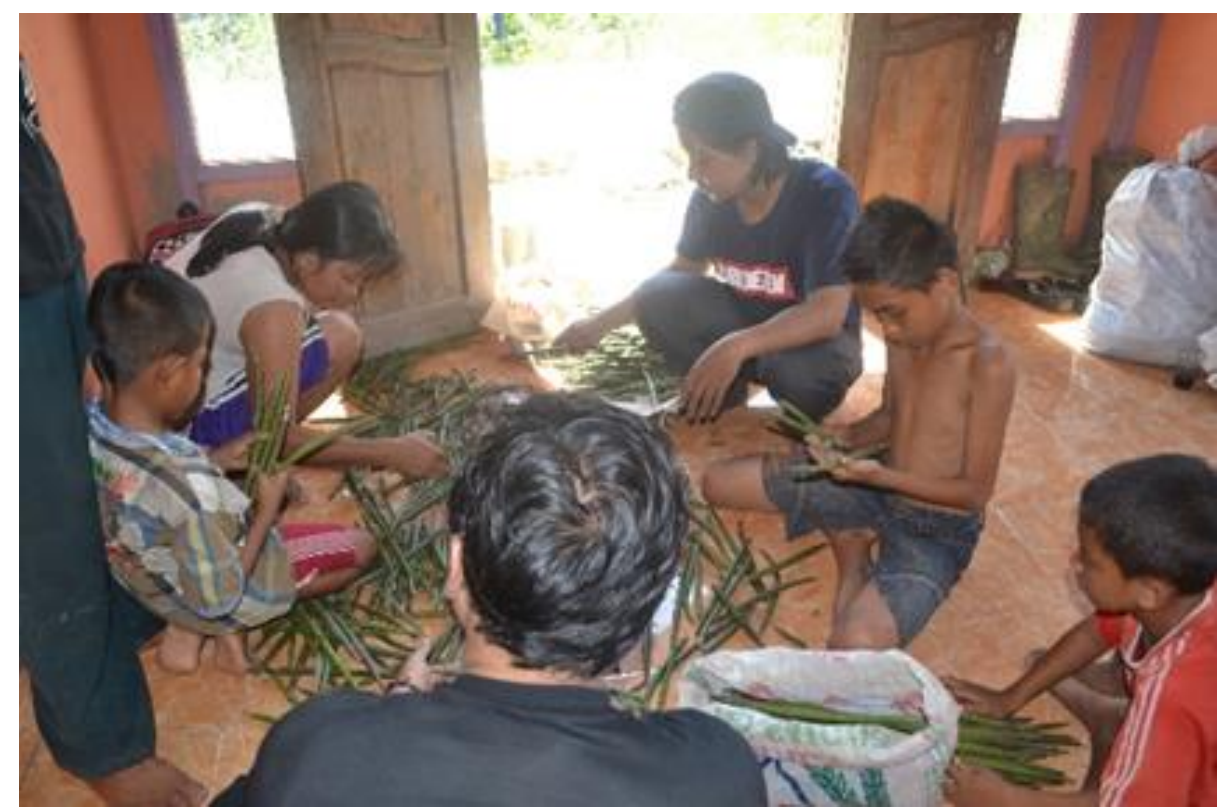

Gambar 2. Pengumpulan dan perhitungan benih mangrove

Untuk melindungi benih mangrove, maka dilakukan pembuatan bedeng sebagai tempat penyemaian bibit mangrove hingga mangrove siap ditanam di pesisir pantai. Saat menanam atau penyemaian, harus memperhatikan beberapa hal, pemilihan tempat sangat penting, misalnya pada tanah yang lapang dan datar, dan pastikan terendam air saat pasang, sehingga tidak memerlukan penyiraman.

Selain pemilihan tempat, pembuatan bedeng penyemaian juga harus diperhatikan, seperti bedeng diberi pelindung ringan dan tipis, kemudian media bedengan berasal dari tanah lumpur di sekitarnya, dan bedeng dibuat dengan ukuran 1,5×3 dengan ketinggian berkisar 1 meter (Gambar 3). Setelah bedeng selesai dibangun, maka dilakukan tahapan persiapan proses pembibitan Mangrove. Pembibitan benih mangrove di dalam polibag dilakukan dengan cara sebagai berikut :

1. Polibag diisi dengan lumpur yang ada disekitar bedeng sebanyak $3 / 4$ dari isi polibag.

2. Lipat bagian atas polibag ke bagian luar, dengan tujuan, pada saat surut dan cuaca kering, kristal-kristal garam tidak terjebak di dalam.

3. Selanjutnya, tanam buah mangrove yang telah dipilih dan berkondisi baik, ke dalam sedimen dengan kedalaman yang cukup.

4. Setelah itu, satu persatu polibag yang sudah terisi dengan buah-buah mangrove tersebut, dimasukkan ke dalam bedeng.

Bibit yang sudah disemai juga dilakukan pemantauan untuk mengetahui perkembangannya hingga mencapai proses pertumbuhan yang siap ditanam di pesisir Mempawah. Proses ini memakan waktu kurang lebih 3 bulan.

Setelah proses penyemaian bibit selesai, mangrove siap ditanam di pesisir Kabupaten Mempawah, tepatnya di Desa Sungai Duri II. Sebelum penanaman, dilakukan pemberian materi dan sosialisasi dari Tim Teknik Lingkungan bekerjasama dengan MMC (Mempawah Mangrove Conservation) yang sukses melakukan konservasi mangrove di Desa Pasir Mempawah kemudian berkembang menjadi lokasi eduwisata. Sosialisasi ini dihadiri sekitar 40 orang dari Desa Mendalok dan Desa Sungai Duri II. Dihadiri oleh Kepala Desa Mendalok dan Kepala 


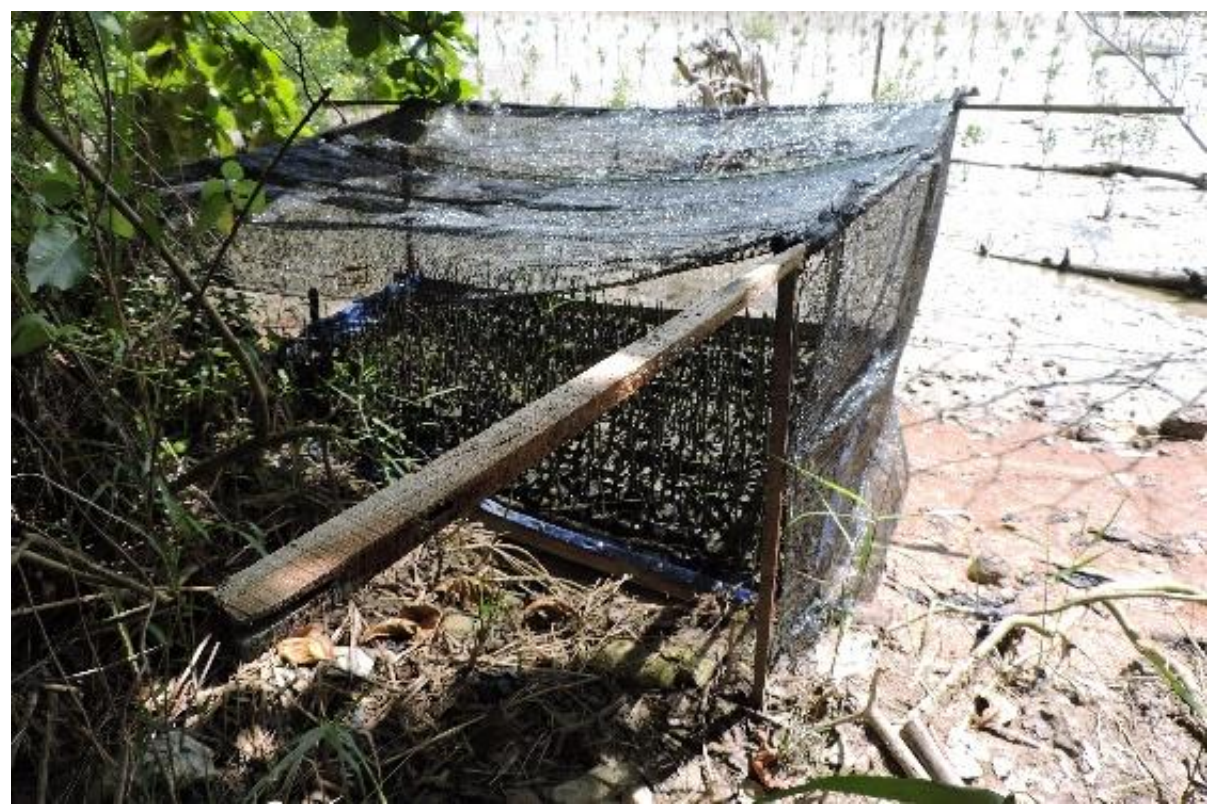

Gambar 3. Penyemaian bibit mangrove di dalam bedeng

Desa Sungai Duri II, Pemuda Karang Taruna Desa Sungai Duri II, serta masyarakat yang peduli dengan konservasi mangrove. Mengingat telah terjadi abrasi yang cukup parah di kawasan pesisir Kabupaten Mempawah. Selain itu juga dilakukan pembentukan Kelompok Pengelola Ekosistem Mangrove Mempawah.

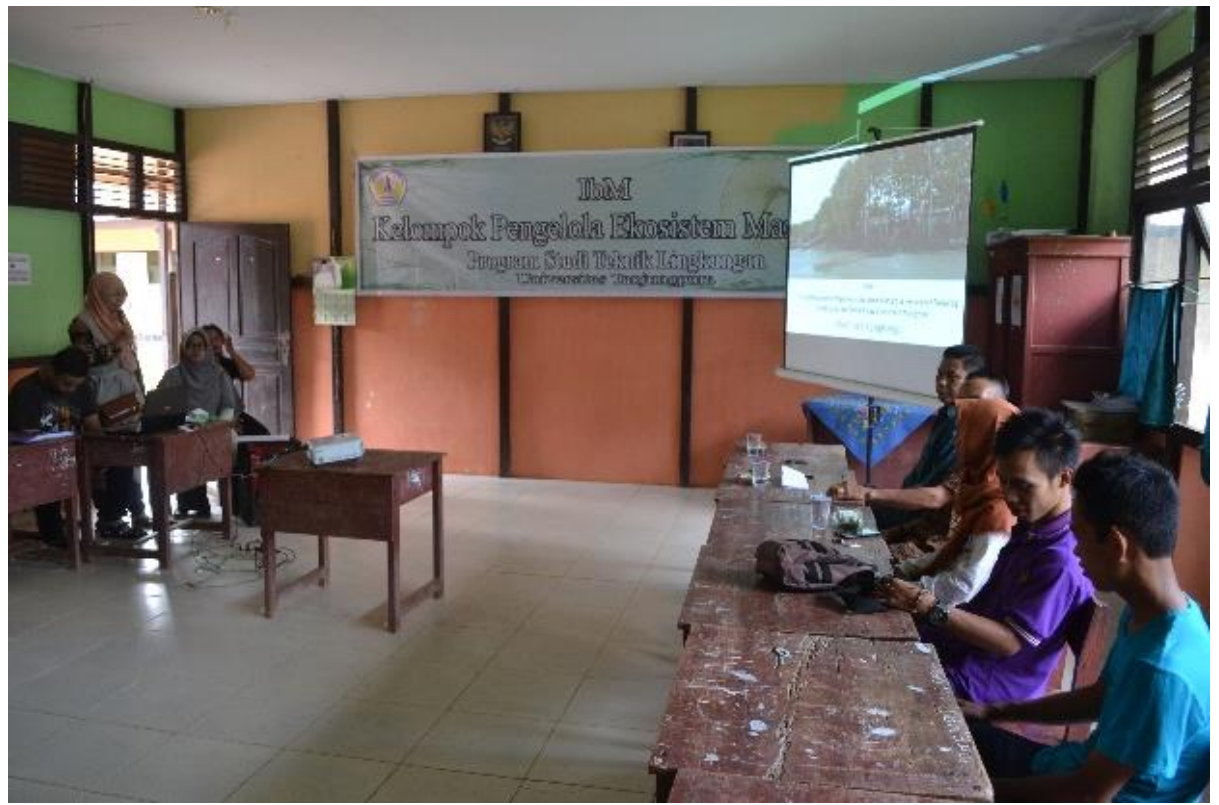

Gambar 4. Sosialisasi dan pembentukan Kelompok Pengelola Ekosistem Mangrove Mempawah

\section{B. Kegiatan Penanaman Mangrove}

Tahapan kegiatan selanjutnya adalah melakukan penanaman Mangrove bersama masyarakat pengelola ekosistem mangrove di Desa Sungai Duri II (Gambar $5-7$ ):

1. Pengangkutan bibit mangrove dari tempat penyemaian

2. Perkirakan jarak tanam untuk pemasangan ajir secara tersusun rapi dan berpola dengan jarak tanam $1-1,5 \mathrm{~m}$ 
3. Pembuatan lubang tanam dengan menggunakan tangan maupun alat bantu sedalam $15-20 \mathrm{~cm}$

4. Membuka polibag dengan cara yang benar

5. Ditanam dengan hati-hati

6. Tutup lubang tanam dan padatkan serta melakukan peninggian tanah

7. Pengikatan mangrove dengan ajir (tidak kencang)

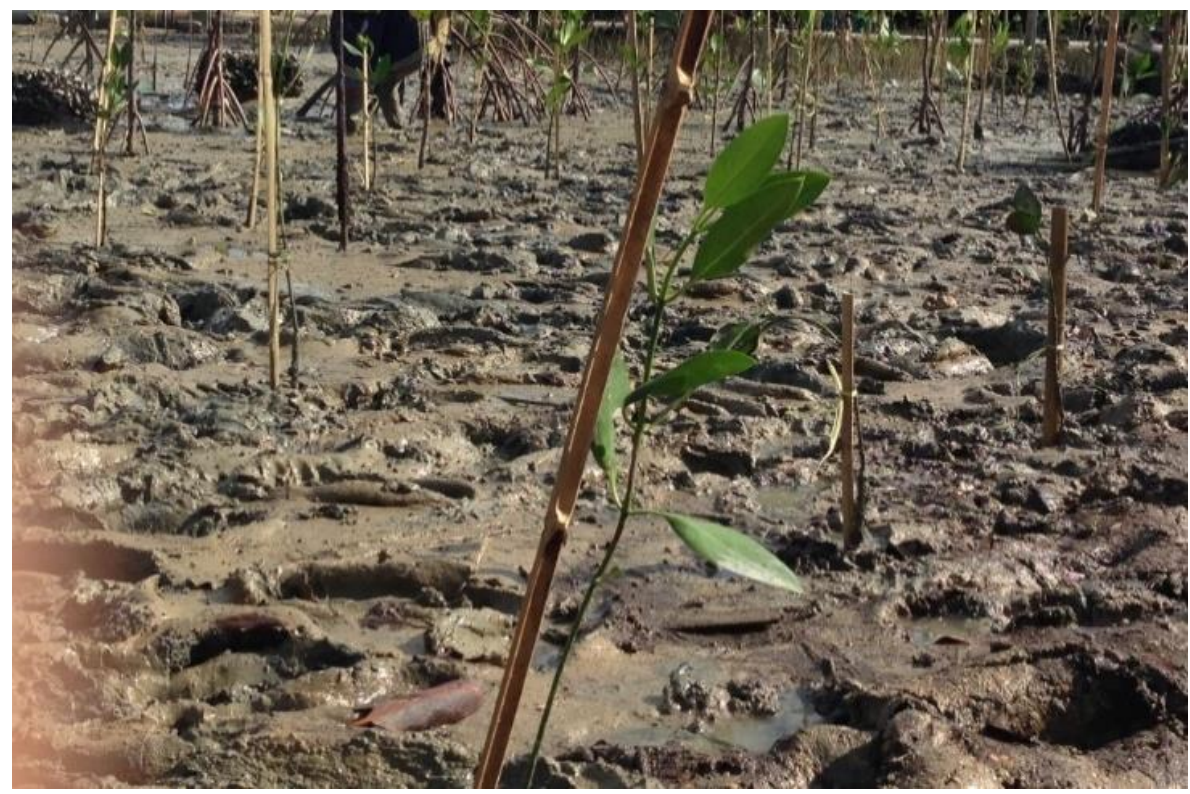

Gambar 5. Mangrove dan ajir yang belum diikat

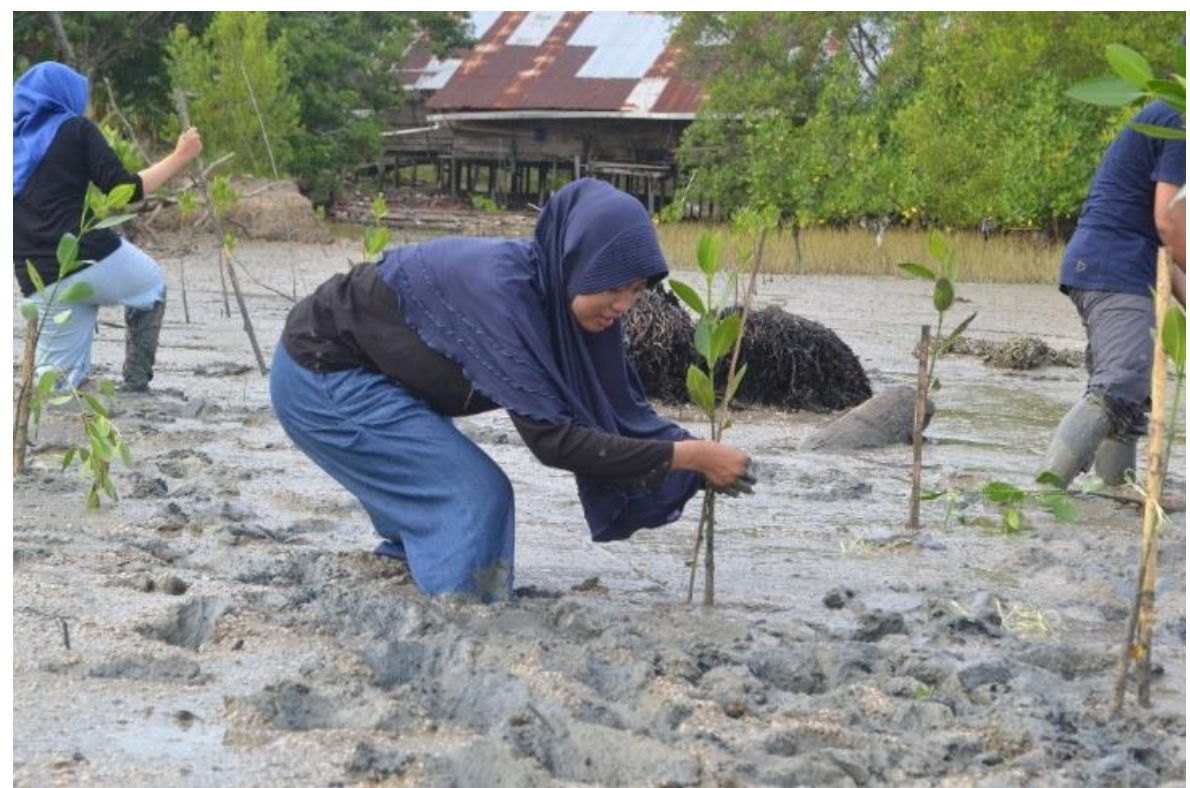

Gambar 6. Pengikatan mangrove dengan ajir bersama masyarakat

\section{Keberhasilan Kegiatan}

Tiga bulan pasca penanaman mangrove, dilakukan kunjungan ke lokasi penanaman mangrove untuk mengevaluasi penanaman. Tanaman mangrove berada di kisaran 60-70\% yang masih bertahan hidup. Terbukti ajir bisa menambah peluang hidup bibit mangrove yang ditanam di pesisir pantai. Hal lainnya yang menyebabkan mangrove tidak bisa hidup, antara lain karena terbawa arus yang kuat, adanya plastik yang menyebabkan mangrove terganggu. Cuaca yang kurang baik juga mempengaruhi peluang keberhasilan penanaman mangrove 


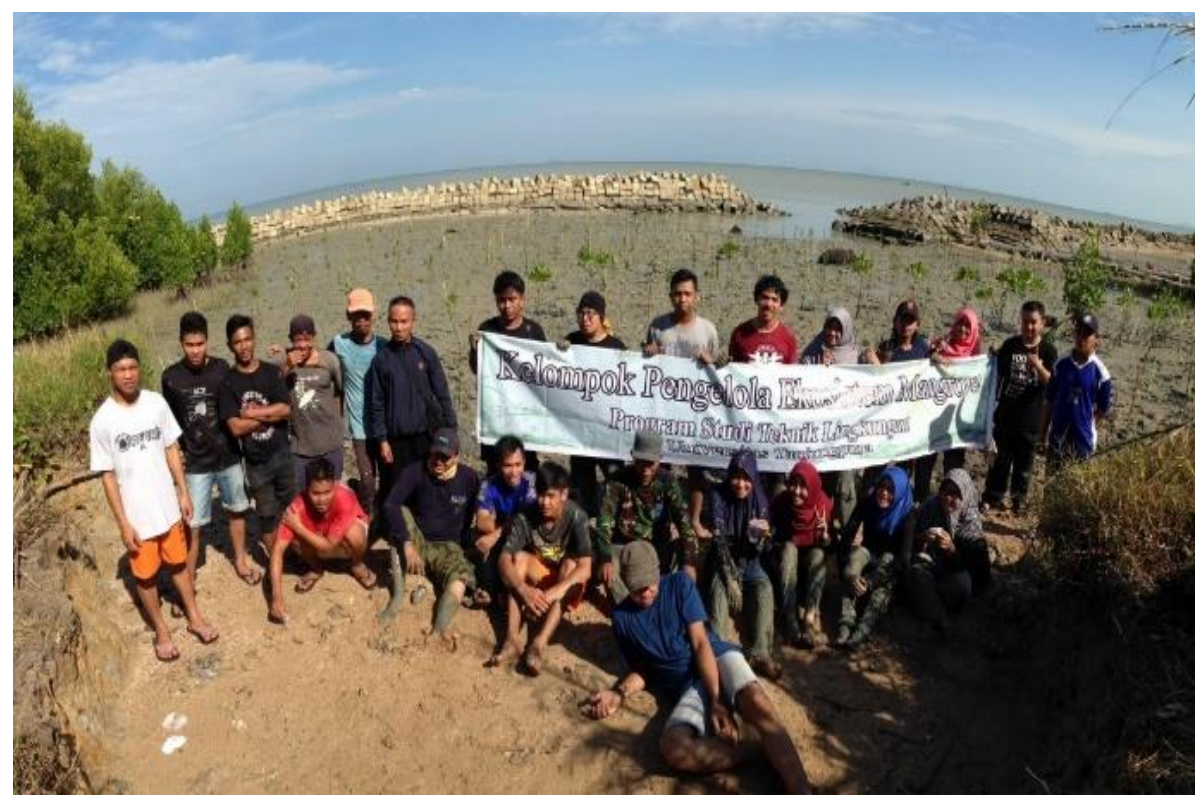

Gambar 7. Foto bersama Tim Pengabdian dengan Kelompok Pengelola Ekosistem Mangrove Mempawah

di pesisir Kabupaten Mempawah. Masyarakat pecinta mangrove yang sudah dibentuk akan terus melakukan penanaman untuk menyelamatkan lahan kritis akibat abrasi. Selain itu juga ada anggota masyarakat yang membudidayakan tanaman mangrove dengan melakukan pembibitan sehingga instansi atau masyarakat yang ingin melakukan penanaman mangrove tidak kesulitan mendapatkan bibit mangrove. Juga telah dibentuk Ekowisata Mangrove di Desa Mendalok. Sehingga bisa menaikkan kesadaran masyarakat mengenai pentingnya mangrove dan bisa menaikkan pendapatan masyarakat. Hal ini tidak terlepas dari bimbingan instansi terkait dan Mempawah Mangrove Conservation yang telah mendirikan kawasan Mempawah Mangrove Park di Desa Pasir yang sangat layak dijadikan percontohan.

\section{Kesimpulan}

Konservasi pada Ekosistem Hutan Mangove harus melibatkan banyak pihak, masyarakat, pemerintah desa, pemerintah daerah, pihak swasta, komunitas/ organisasi masyarakat, organisasi pemuda, dan lain sebagainya. Pelaksanaan kegiatan konservasi, dapat mereboisasi dan mengurangi luasan lahan kritis mangrove yang ada di wilayah pesisir sehingga mencegah abrasi yang terjadi di Kabupaten Mempawah, Provinsi Kalimantan Barat.

\section{Ucapan Terima Kasih}

Penulis mengucapkan terima kasih kepada masyarakat Desa Sungai Duri II, Desa Mendalok dan Desa Pasir Kabupaten Mempawah, serta Mempawah Mangrove Conservation. Kegiatan ini terlaksana dengan dibiayai Program IbM Tahun 2016 oleh Direktorat Riset dan Pengabdian Masyarakat, Direktorat Jenderal Penguat Riset dan Pengembangan Kementerian Riset, Teknologi dan Pendidikan Tinggi.

\section{Referensi}

Ahmad, D.N. (2017). Penyuluhan dan Pelatihan Upaya Pencegahan Abrasi Pantai Pada Masyarakat Muara Gembong Bekasi. Jurnal Panrita Abdi, 1(2): 90-96.

Badan Pusat Statistik (BPS) Kalimantan Barat. (2002). Kalimantan Barat Dalam Angka 2002. Kalimantan Barat: BPS Kalimantan Barat. 
Badan Pusat Statistik (BPS) Kabupaten Pontianak. (2011). Kabupaten Pontianak Dalam Angka 2011. Kabupaten Pontianak: BPS Kabupaten Pontianak.

Bapedalda Provinsi Kalimantan Barat. 2003. Basis Data Lingkungan Hidup Propinsi Kalimantan Barat.

Noor, Y.R., Khazali, M., \& Suryadiputra, I.N.N. (2012). Guides introduction of mangroves in Indonesia, Bogor, Indonesia.

Siburian, R., \& Haba, J. (2016). Introduction: Mangrove and Coastal Communities.

Giesen, W. (1993). Indonesia's Mangroves: An Update on Remaining Area and Main Management Issues. In Seminar "Coastal Zone Management of Small Island Ecosystems", Ambon, 7-10 April 1993.

Yani, E.I., Hoslaily, A., \& Harahap, N. (2006) "Economic Evaluation of Mangrove Forests in District Nguling, Pasuruan in East Java, in L. Adrianto, A.H. Purnomo, Proceedings of the National Workshop on the Economic and Social Research of Marine and Fisheries, Jakarta.

Penulis:

Laili Fitria, Jurusan Teknik Lingkungan, Fakultas Teknik, Universitas Tanjungpura, Makassar. Email: fitria.laili@gmail.com

Yulisa Fitrianingsih, Jurusan Teknik Lingkungan, Fakultas Teknik, Universitas Tanjungpura, Makassar. E-mail: icha_jolie@yahoo.com

Jumiati, Jurusan Teknik Lingkungan, Fakultas Teknik, Universitas Tanjungpura, Makassar. E-mail: tljumiati@gmail.com

Bagaimana men-sitasi artikel ini:

Fitria, L., Fitrianingsih, Y., \& Jumiati, J. (2020). Penerapan Teknologi Penanaman Mangrove di

Kabupaten Mempawah Provinsi Kalimantan Barat, Indonesia. Jurnal Panrita Abdi, 4 (2), 126 - 135. 